\title{
THE
}

2013

\section{Chiral cationic polyamines for chiral microcapsules and siRNA delivery}

Justin Gharavi

University of Rhode Island

Patricks Marks

University of Rhode Island

Kelly Moran

University of Rhode Island

Brett Kingsborough

University of Rhode Island

Ruchi Verma

University of Rhode Island

Follow this and additional works at: https://digitalcommons.uri.edu/chm_facpubs

This is a pre-publication author manuscript of the final, published article.

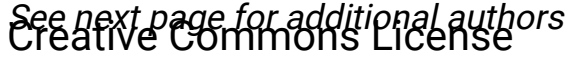

(c) (i) $\Theta \Theta$

This work is licensed under a Creative Commons Attribution-Noncommercial-No Derivative Works 4.0 License.

\section{Citation/Publisher Attribution}

Gharavi, J., Marks, P., Moran, K., Kingsborough, B., Verma, R., Chen, Y., Deng, R., \& Levine, M. (2013). Chiral cationic polyamines for chiral microcapsules and siRNA delivery. Bioorganic \& Medicinal Chemistry Letters, 23(21), 5919-5922. doi: 10.1016/j.bmcl.2013.08.083

Available at: https://doi.org/10.1016/j.bmcl.2013.08.083

This Article is brought to you for free and open access by the Chemistry at DigitalCommons@URI. It has been accepted for inclusion in Chemistry Faculty Publications by an authorized administrator of DigitalCommons@URI. For more information, please contact digitalcommons-group@uri.edu. 


\section{Authors}

Justin Gharavi, Patricks Marks, Kelly Moran, Brett Kingsborough, Ruchi Verma, Yuan Chen, Ruitang Deng, and Mindy Levine

This article is available at DigitalCommons@URI: https://digitalcommons.uri.edu/chm_facpubs/136 


\title{
Chiral Cationic Polyamines for Chiral Microcapsules and siRNA Delivery
}

\author{
Justin Gharavi ${ }^{\mathrm{a}}$, Patrick Marks ${ }^{\mathrm{a}}$, Kelly Moran ${ }^{\mathrm{a}}$, Brett Kingsborough ${ }^{\mathrm{a}}$, Ruchi Verma ${ }^{\mathrm{b}}$, Yuan \\ Chen $^{\mathrm{b}}$, Ruitang Deng ${ }^{\mathrm{b}}$, and Mindy Levine ${ }^{\mathrm{a},{ }^{*}}$ \\ aDepartment of Chemistry, University of Rhode Island, 51 Lower College Road, Kingston, RI \\ 02881 \\ ${ }^{\text {bC }}$ ollege of Pharmacy, University of Rhode Island, 7 Greenhouse Road, Kingston, RI 02881
}

Polyethyleneimines (PEIs) are a well-studied class of polymers. ${ }^{1,2}$ These polymers are synthesized commercially via the ring opening of aziridine (Scheme 1, Reaction 2), ${ }^{3-5}$ although this process leads to highly branched polymers ${ }^{6}$ with significant polydispersity indexes. The controlled synthesis of linear PEIs occurs via the cationic ring opening of oxazolines ${ }^{7-9}$ followed by hydrolysis of the resulting formamides (Scheme 1, Reaction 1). Using chiral oxazolines as substrates for the polymerization reaction provides straightforward access to homochiral PEIs, ${ }^{10-12}$ with chiral centers at every polymer repeat unit.

The significant interest in PEIs is driven largely by various applications of PEIs in fields including chiral catalysis, ${ }^{13-16}$ drug delivery, ${ }^{17,18}$ and oligonucleotide complexation and delivery. ${ }^{19,20}$ PEIs have also been covalently linked to form PEI-derived microcapsules, ${ }^{21}$ which have been used for site-isolated catalysis. ${ }^{22,23}$ In one example, the Lewis basic PEI catalyzed a reaction in the same reaction vessel as a Lewis acidic nickel catalyst, which was used to catalyze the second reaction. ${ }^{24,25}$

Use of the same PEI scaffold for multiple applications has rarely been reported, although such multi-purpose polymers would have significant operational advantages. Reported herein is the use of a single PEI scaffold for two purposes: the fabrication of covalentlylinked chiral microcapsules, and the efficient delivery of siRNA to Huh7 cells. ${ }^{26}$

The chiral PEIs were synthesized via the cationic polymerization of 4-benzyl-2-oxazoline (1a) (both $R$ and $S$ configurations), followed by the hydrolysis of the initially formed polyformamide (Scheme 2). The resulting polymers were characterized by ${ }^{1} \mathrm{H}$ NMR spectroscopy, and the results were in agreement with literature-reported spectra. ${ }^{11}$ Using this methodology, polymers with 13 and 30 repeat units were formed, with both $R$ and $S$ configured side chains.

Once synthesized, the homochiral PEIs were cross-linked to form homochiral microcapsules following the procedure developed by McQuade and co-workers. ${ }^{22}$ Briefly, polymers 2a

() 2013 Elsevier Ltd. All rights reserved.

"Corresponding author: mlevine@chm.uri.edu; 401-874-4243.

Supplementary Data: Supplementary data associated with this article can be found in the online version.

Publisher's Disclaimer: This is a PDF file of an unedited manuscript that has been accepted for publication. As a service to our customers we are providing this early version of the manuscript. The manuscript will undergo copyediting, typesetting, and review of the resulting proof before it is published in its final citable form. Please note that during the production process errors may be discovered which could affect the content, and all legal disclaimers that apply to the journal pertain. 
were dissolved in methanol, and added to a solution of $2 \%$ Span 85 , followed by the addition of 2,4-tolylene diisocyanate (TDI, compound 7) (Equation 1), which cross linked the microcapsules to form a polyurea coating. ${ }^{25}$ The resulting polyurethane-type structures have been shown to be stable in a variety of aqueous media. ${ }^{27,28}$ After thorough solvent evaporation, chiral microcapsules were obtained.

The resulting microcapsules were imaged using transmission electron microscopy (TEM), and some images are shown in Figure 1. The diameters of the particles ranged from $57 \mathrm{~nm}-$ $250 \mathrm{~nm}$, with an average diameter of $141 \mathrm{~nm}( \pm 35 \mathrm{~nm} ; 62$ particles measured). These new supramolecular architectures contain narrow size distributions and uniform structures, in good agreement with literature-reported results for achiral microcapsule analogues. ${ }^{21}$

The newly formed microcapsules contain a variety of features that make them particularly amenable to supramolecular chiral catalysis, including: (a) multiple chiral centers, covalently confined in a small space; (b) multiple amino groups that can be protonated or deprotonated over a wide $\mathrm{pH}$ range ${ }^{29}$ and (c) a hydrophobic core resulting from the hydrophobic benzyl side chains. ${ }^{30}$

To investigate the effect of capsule formation on the resulting supramolecular chiral environment, the newly synthesized chiral microcapsules were used as catalysts for the transamination reaction of ketoacids to amino acids (Equation 2). Obtaining good enantioselectivities in such transamination reactions has been an ongoing research problem. ${ }^{10}$ Preliminary results indicate that the microcapsule-catalyzed reactions proceeded with significantly higher enantioselectivities compared to the polymer-catalyzed reactions (up to $20 \%$ enantiomeric excess (ee) obtained for the synthesis of L-valine, under conditions where the polymer itself yielded $4 \%$ ee). Efforts to optimize the reaction conditions are in progress.

Interestingly, the chiral PEIs also functioned as efficient siRNA delivery agents. Although there are many reported examples of PEIs used for siRNA and DNA delivery, ${ }^{31-33}$ many of these delivery vehicles suffer from high cytotoxicity. ${ }^{34}$ The development of gene delivery agents that are both effective and less toxic remains a highly relevant research objective.

The following 4 polymers were investigated as potential siRNA delivery agents: $R$-2a-13; $S-2 \mathbf{a}-13 ; R-6-13$; and $S-6-13$, where the R/S designation refers to the chirality of the side chain and the number 13 refers to the number of repeat units in the polymers. The efficacy of these polymers in transfecting an Alexa488-labeled control siRNA sequence ${ }^{35}$ to Huh7 cells $^{36}$ was measured by determining the intracellular fluorescence 24 hours posttransfection. The results obtained using the chiral polyamines were compared to results obtained using commercially available transfection reagents: Genjet siRNA Transfection Reagent (SignaGen Laboratories); HiPerFect Transfection Reagent (Qiagen Laboratories); ${ }^{37}$ and Lipofectamine 2000 (Invitrogen Technologies). ${ }^{38}$

Figure 2 shows a graph of the intracellular fluorescence of Huh7 cells following their incubation with Alexa-labeled siRNA with various delivery reagents. The intracellular fluorescence obtained with compounds $S-6-13$ and $S-\mathbf{2 a - 1 3}$ is substantially higher than the fluorescence observed with positive controls Lipofectamine and Genjet, indicating the polymers' ability to transfect siRNA efficiently (Table 1). More interestingly, compounds $R-2 \mathbf{a}-13$ and $R-\mathbf{6}-13$, which are identical except for the three-dimensional configuration of the benzyl group, transfect siRNA with approximately the same efficiency as Lipofectamine and Genjet, and substantially lower than the "enantiomeric" polymers.

The chirality of the side chains of the PEIs thus has a direct and measurable effect on the ability of PEIs to transfect siRNA efficiently: $S$ chiral centers (compounds $S-6-13$ and 
S-2a-13) transfect siRNA more efficiently than the R analogues. Such a result may seem intuitive: that the interaction of two chiral macromolecules (chiral PEI and chiral siRNA) depends on the three-dimensional configuration of both molecules. This intuition is borne out by the results of this study, which is the first direct proof that the chirality of a polyamine directly impacts its transfection efficiency. Similar effects of the chirality on transfection efficiency were recently observed for the lipid delivery agent 1,2-dioleoyl-3trimethylammonium-propane (DOTAP) ${ }^{39}$ In that report, the $R$ enantiomer performed better than either the $S$ enantiomer or the racemic DOTAP mixture.

The toxicity of the newly synthesized PEIs was tested using an MTT assay. ${ }^{40}$ After 24 hours of incubation, the absorbance of the cells was quantified and the cell viability was calculated. Using $1000 \mathrm{nM}$ of $S$-2a-13 reduced the cell viability to $88 \%$, and $1000 \mathrm{nM}$ of $S-6-13$ reduced it to $82 \%$. By comparison, Lipofectamine reduced cell viability to $89 \%$, and compounds $R-\mathbf{2 a}-13$ and $R-\mathbf{6}-13$ reduced viability to $78 \%$ and $71 \%$. Thus, the toxicity of the chiral PEIs, like the transfection efficiency, depends on the three-dimensional configuration of the benzylic side chains.

The differences in transfection efficiency and toxicity mean that the $S$ - and $R$-configured PEIs likely have fundamentally different three-dimensional architectures. The relationship between the chirality of individual stereocenters and the overall polymer configuration has been studied for related polymers using circular dichroism spectroscopy. ${ }^{41-43}$ These differences in chirality affect the polymers' solubility ${ }^{44}$ and their interactions with DNA, ${ }^{45}$ and as shown here, their transfection efficiencies.

In summary, chiral polymers $\mathbf{6}$ and $\mathbf{2 a}$ were synthesized via straightforward, wellprecedented procedures. These polymers were used for two novel applications: the fabrication of chiral, covalently-linked microcapsules, and the transfection of siRNA to Huh7 cells. The chiral microcapsules can be used for a number of potential applications in supramolecular chiral catalysis and in supramolecular enantiomer separations. The chiralitydependent siRNA transfection also provides an intriguing platform for further investigation. In particular, polymer $S$-2a-13 demonstrated good transfection efficiency and limited toxicity, and will be used for further biochemical investigations. The results of these and other experiments will be reported in due course.

\section{Supplementary Material}

Refer to Web version on PubMed Central for supplementary material.

\section{Acknowledgments}

This work was supported by an Institutional Development Award (IDeA) from the National Institute of General Medical Sciences of the National Institutes of Health under grant number 8 P20 GM103430-12 to M. L. R. D. is supported by the National Institutes of Health (NIH) (Grant No.: R01DK087755).

\section{References}

1. Jaeger M, Schubert S, Ochrimenko S, Fischer D, Schubert US. Chem Soc Rev. 2012; 41:4755. [PubMed: 22648524]

2. Nimesh S. Curr Clinical Pharmacol. 2012; 7:121.

3. Kircheis R, Wightman L, Wagner E. Adv Drug Delivery Rev. 2001; 53:341.

4. Rivas BL, Geckeler KE. Adv Polym Sci. 1992; 102:171.

5. Jones GD, Langsjoen A, Neumann MMC, Zomlefer J. J Org Chem. 1944; 9:125.

6. Chaikittisilp W, Didas SA, Kim HJ, Jones CW. Chem Mater. 2013; 25:613. 
7. Kagiya T, Narisawa S, Maeda T, Fukui K. J Polym Sci B Polym Lett. 1966; 4:441.

8. Saegusa T, Ikeda H, Fujii H. Macromolecules. 1972; 5:108.

9. Saegusa T, Ikeda H, Fujii H. Polym J. 1972; 3:35.

10. Levine M, Kenesky CS, Zheng S, Quinn J, Breslow R. Tetrahedron Lett. 2008; 49:5746. [PubMed: 19794811]

11. Bandyopadhyay S, Zhou W, Breslow R. Org Lett. 2007; 9:1009. [PubMed: 17316011]

12. Viegas TX, Bentley MD, Harris JM, Fang Z, Yoon K, Dizman B, Weimer R, Mero A, Pasut G, Veronese FM. Bioconjugate Chem. 2011; 22:976.

13. Zhou W, Yerkes N, Chruma JJ, Liu L, Breslow R. Bioorg Med Chem Lett. 2005; 15:1351. [PubMed: 15713385]

14. Kano T, Konishi S, Shirakawa S, Maruoka K. Tetrahedron Asymm. 2004; 15:1243.

15. Bellis E, Kokotos G. J Molec Catal A Chem. 2005; 241:166.

16. Subhani MA, Mueller KS, Eilbracht P. Adv Synth Catal. 2009; 351:2113.

17. Kumar KS, Madhusudhanan J, Thanigaivel, Robin A, Veni VA. Res J Biotechnol. 2013; 8:70.

18. Dong DW, Xiang B, Gao W, Yang ZZ, Li JQ, Qi XR. Biomater. 2013; 34:4849.

19. Glebova KV, Marakhonov AV, Baranova AV, Skoblov MY. Molec Biol. 2012; $46: 349$.

20. Nakayama Y. Acc Chem Res. 2012; 45:994. [PubMed: 22353143]

21. Longstreet AR, McQuade DT. Acc Chem Res. 2013; 46:327. [PubMed: 23072456]

22. Mason BP, Hira SM, Strouse GF, McQuade DT. Org Lett. 2009; 11:1479. [PubMed: 19254010]

23. Mason BP, Bogdan AR, Goswami A, McQuade DT. Org Lett. 2007; 9:3449. [PubMed: 17645350]

24. Poe SL, Kobaslija M, McQuade DT. J Am Chem Soc. 2006; 128:15586. [PubMed: 17147357]

25. Poe SL, Kobaslija M, McQuade DT. J Am Chem Soc. 2007; 129:9216. [PubMed: 17602626]

26. Ludwig H. Blood. 2010; 116:3383. [PubMed: 21051564]

27. Baier G, Musyanovych A, Dass M, Theisinger S, Landfester K. Biomacromolecules. 2010; 11:960. [PubMed: 20329746]

28. Lu Y, Larock RC. Biomacromolecules. 2007; 8:3108. [PubMed: 17877401]

29. Griffiths PC, Paul A, Fallis IA, Wellappili C, Murphy DM, Jenkins R, Waters SJ, Nilmini R, Heenan RK, King SM. J Coll Interface Sci. 2007; 314:460.

30. Bellettini IC, Nandi LG, Eising R, Domingos JB, Machado VG, Minatti E. J Coll Interface Sci. 2012; 370:94.

31. Wang Y, Su J, Cai W, Lu P, Yuan L, Jin T, Chen S, Sheng J. Drug Design Devel Therapy. 2013; 7:211.

32. Zhang QF, Yi WJ, Wang B, Zhang J, Ren L, Chen QM, Guo L, Yu XQ. Biomaterials. 2013; 34:5391. [PubMed: 23582685]

33. Chu M, Dong C, Zhu H, Cai X, Dong H, Ren T, Su J, Li Y. Polymer Chem. 2013; 4:2528.

34. Parhamifar L, Larsen AK, Hunter AC, Andresen TL, Moghimi SM. Soft Matter. 2010; 6:4001.

35. Alabi CA, Love KT, Sahay G, Stutzman T, Young WT, Langer R, Anderson DG. ACS Nano. 2012; 6:6133. [PubMed: 22693946]

36. Xing, X-k; Li, S-j; He, J-1; Chen, Z. Biotechnol Lett. 2012; 34:295. [PubMed: 21972147]

37. Bakhshandeh B, Soleimani M, Hafizi M, Ghaemi N. Cytotechnology. 2012; 64:523. [PubMed: 22328133]

38. Mo RH, Zaro JL, Ou JHJ, Shen WC. Molec Biotechnol. 2012; 51:1. [PubMed: 21660602]

39. Terp MC, Bauer F, Sugimoto Y, Yu B, Brueggemeier RW, Lee LJ, Lee RJ. Int J Pharmaceutics. 2012; 430:328.

40. Jiang G, Park K, Kim J, Kim KS, Oh EJ, Kang H, Han SE, Oh YK, Park TG, Hahn SK. Biopolym. 2008; 89:635.

41. Luxenhofer R, Huber S, Hytry J, Tong J, Kabanov AV, Jordan R. J Polym Sci A Polym Chem. 2013; 51:732.

42. Bloksma MM, Rogers S, Schubert US, Hoogenboom R. Soft Matter. 2010; 6:994.

43. Hoogenboom R, Schlaad H. Polym. 2011; 3:467. 
44. Bloksma MM, Rogers S, Schubert US, Hoogenboom R. J Polym Sci A Polym Chem. 2011; 49:2790.

45. Yoshikawa Y, Umezawa N, Imamura Y, Kanbe T, Kato N, Yoshikawa K, Imanaka T, Higuchi T. Angew Chem Int Ed. 2013; 52:3712. 

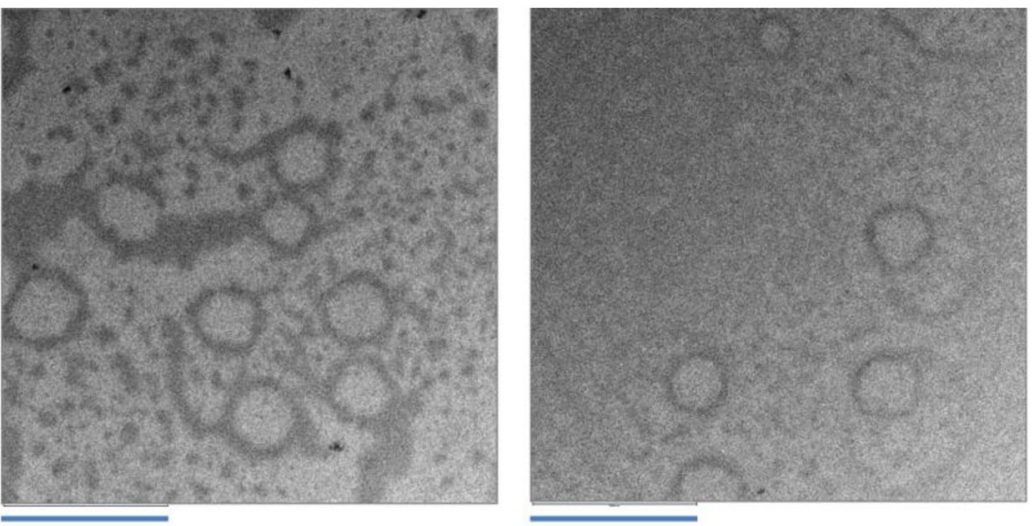

Figure 1.

TEM images of chiral microcapsules 8 (Blue line represents a $500 \mathrm{~nm}$ scale) 


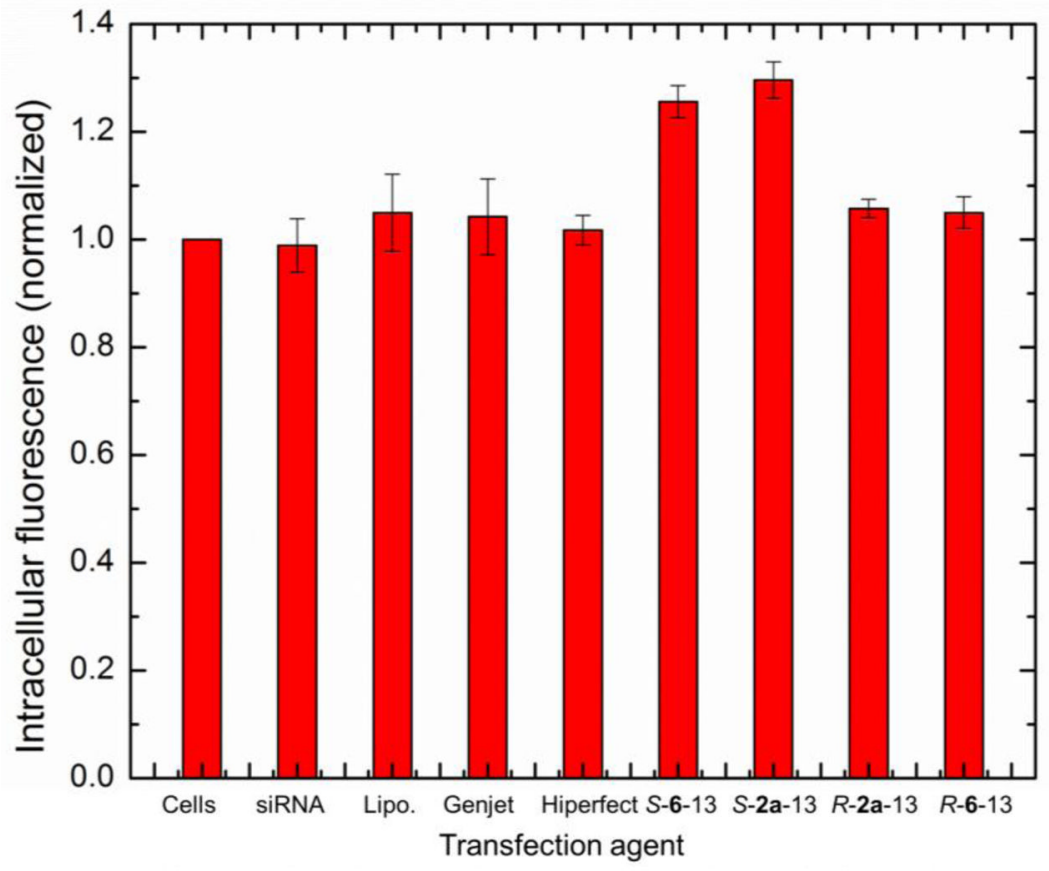

Figure 2.

Chart of the intracellular fluorescence of Huh7 cells after transfection with siRNA (all PEIs were used at a $1000 \mathrm{nM}$ final concentration) 

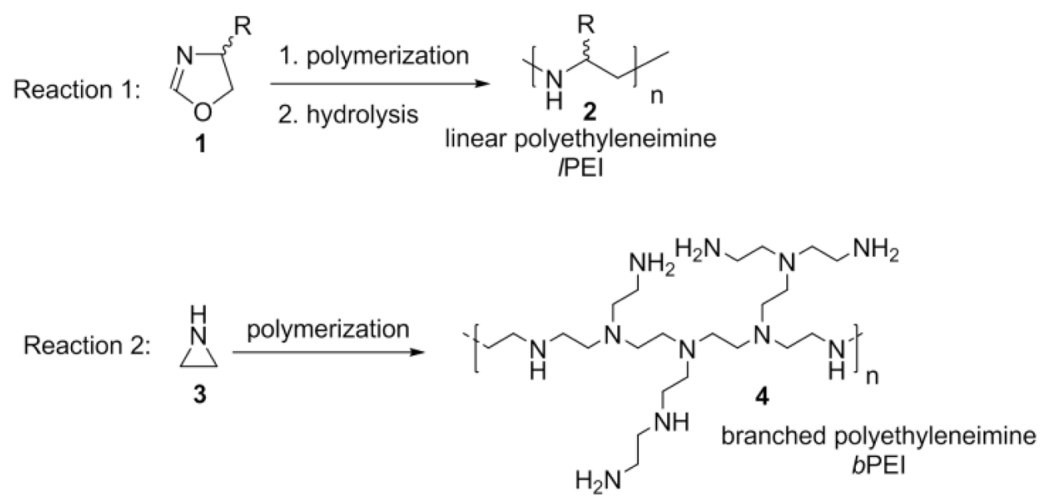

Scheme 1.

General synthetic methods for linear and branched polyethyleneimine (PEI) 

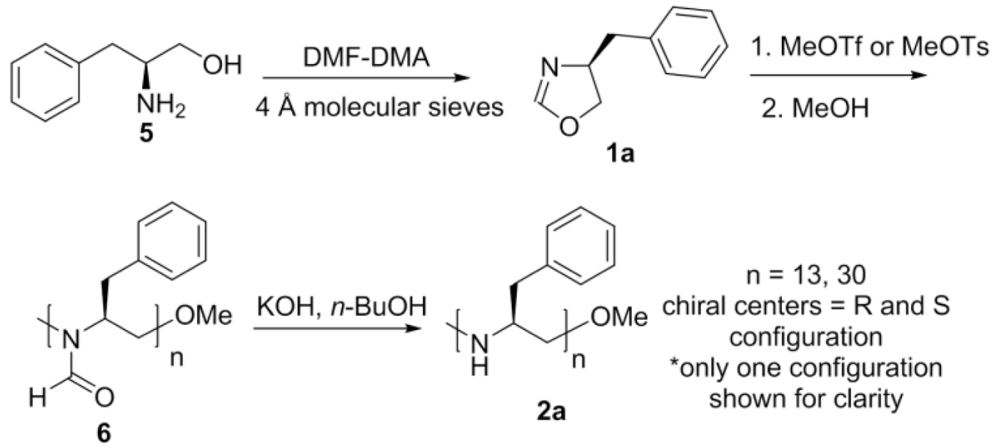

Scheme 2.

Synthesis of chiral polymers 2a 

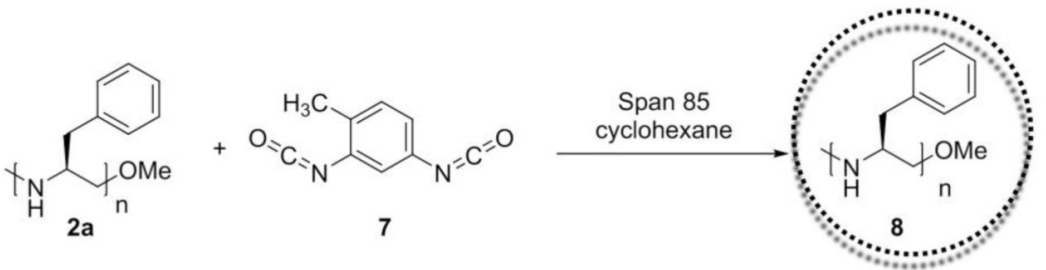

Equation 1.

Synthesis of chiral covalently-linked microcapsules 


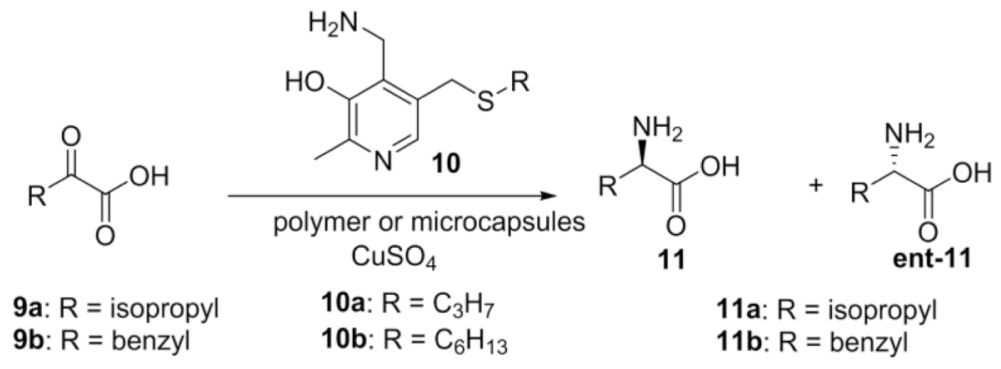

Equation 2.

Enantioselective transamination of ketoacids $\mathbf{9}$ to amino acids $\mathbf{1 1}$ 
Table 1

Transfection efficiencies of chiral PEIs and commercial transfection agents

\begin{tabular}{|c|c|}
\hline Transfection agent & Intracellular fluorescence (normalized to 1.00 for cells alone) \\
\hline$S-6-13$ & 1.26 \\
\hline$S-2 a-13$ & 1.30 \\
\hline Lipofectamine & 1.05 \\
\hline Genjet & 1.04 \\
\hline$R$-2a-13 & 1.06 \\
\hline$R-6-13$ & 1.05 \\
\hline
\end{tabular}

